\title{
RANCANGAN SISTEM INFORMASI PROMOSI DAN PEMASARAN OBJEK WISATA GURAICI HALMAHERA SELATAN
}

\section{DESIGN INFORMATION SYSTEMS PROMOTION AND MARKETING OF TOURISM OBJECT GURAICI SOUTH HALMAHERA}

\author{
Arisandy Ambarita ${ }^{1}$, Darman Umagapi ${ }^{2}$, Muharto $^{3}$ \\ Program Studi Manajemen Informatika, \\ Politeknik Sains dan Teknologi Wiratama Maluku Utara \\ arisandy.ambarita@gmail.com
}

\begin{abstract}
Abstrak
Penelitian ini bertujuan untuk merancang Sistem Informasi Promosi dan Pemasaran Objek Wisata Guraici Kabupaten Halmahera Selatan. Analisis sistem menggunakan model driven dengan pendekatan bottom-up yaitu membuat rancnagan sistem secara umum menggunakan alat bantu flowchart. System dibuat mulai dari admin yang berfungsi untuk mengelola system, kemudian media penyimpanan sampai pada luaran sistem. Sedangkan pengembangan sistem menggunakan model Waterfall. Penelitian menghasilkan sistem informasi berbasis website (web), sebagai media promosi dan pemasaran objek wisata Guraici. Sistem informasi ini dapat menjangkau masayarakat di seluruh dunia, serta memudahkan masyarakat mengakses objek dan produk wisata yang ada di Desa Guraici.
\end{abstract}

\section{Kata kunci: Rancangan, Sistem Infromasi, Promosi, Pemasaran, Objek} Wisata, Guraici.

\begin{abstract}
This study aims to design a Promotion and Marketing Information System of Tourism Object in Guraici, South Halmahera Regency. The Systems analysis used a model-driven with a bottom-up approach that is making the system design in general by used a flowchart tool. The system is created starting from the admin that functions to manage the system, then the storage media to the system output. While the system development used the Waterfall model. The research resulted in a website-based information system (web), as a media of promotion and marketing of Guraici attractions. This information system can reach communities all over the world, as well as facilitate people accessing tourist objects and products in the Village of Guraici
\end{abstract}


Keywords: Design, Information Systems, Promotion, Marketing, Tourism Objects, Guraici

\section{PENDAHULUAN}

Indonesia pada saat ini menghadapai berbagai persoalan makro berupa defisit perdagangan luar negeri, pengangguran dan lemahnya pertumbuhan ekonomi [1]. Sector pariwisata dapat diandalkan untuk mengatasi masalah tersebut, karena sektor pariwisata dapat mempekerjakan semua level masyarakat, dan menyediakan arus masuk mata uang asing [2]. Hal ini mendapat pembuktian empiris melalui beberapa penelitian, diantaranya Buckley [3], Swarbrooke [4], Muljadi dan Warman [5], Ramdas dan Mohamed [6], Othman dan Rosli [7]. Kontribusi pariwisata bagi perekonomian nasional Indonesia dapat dilihat dari penyerapan tenaga kerja sebanyak $9,00 \%$, di tahun 2014 atau sekitar 10,32 juta orang yang berada pada sektor-sektor terkait kepariwisataan dan berkembang menjadi 12 juta orang di tahun 2016 [8]. Peningkatan ini memposisikan pariwisata sebagai penghasil devisa negara terbesar di posisi ke-4 setelah minyak \& gas bumi, batubara, dan kelapa sawit. Di tahun 2016 kontribusi pariwisata semakin solid sehingga meningkat pada posisi ke-3 penghasil devisa negara dengan menggeser posisi batu bara [8].
Kabupaten Halmahera Selatan (Halsel) merupakan salah satu daerah yang memiliki potensi pariwisata yang menarik perhatian para wisatawan. Pada tahun 2017, jumlah wisatawan domestik yang berkunjung ke Halmahera Selatan ada sebanyak 926 orang dan wisatawan mancanegara sebanyak 109 orang [9]. Terdapat lima objek wisata unggulan yang tersebar di Halsel, diantaranya adalah Pulau Nusara, Pantai Dermaga Biru, Sibela Beach dan Pulau Guraici. Wawancara dengan Masyarakat Halsel (Agustus, 2018), diketahui bahwa Pulau Guraici merupakan objek wisata paling banyak mendatangkan wisatawan mancanegara. Namun selama 10 Tahun terakhir sudah mulai kehilangan pengunjung. Hal ini berdampak pada daya saing pariwisata, sebagaimana hasil penelitian Muharto et al, pada tahun 2017 indeks pariwisata Halsel berada pada peringkat paling bawah [10]. Salah satu penyebab kegagalan pariwisata Guraici adalah pengelolaan pariwisata yang tidak inovatif dalam memanfaatkan kemajuan teknologi informasi. Sistem promosi dan pemasaran Pariwisata Guraici masih bersifat tradisional, sehingga tidak dapat menjangkau masayarakat luas. 
Padahal, pemanfaatan teknologi dalam sektor pariwisata sangat penting, sebagaimana dikemukakan oleh Muharto bahwa inovasi pemanfaatan sistem informasi promosi dan pemasaran pariwisata merupakan strategi yang dapat meningkatkan daya saing pariwisata [11].

Sejalan dengan uraian di atas, maka diperlukan penelitian tentang Sistem Informasi Promosi dan Pemasaran Objek Wisata, agar dapat menjangkau masyarakat secara lebih luas. Sebagaimana ditunujukkan beberapa hasil penelitian terdahulu bahwa ICT memfasilitasi individu untuk mengakses informasi produk pariwisata dari mana saja setiap saat [12]. Aplikasi Virtual Tour Berbasis Web dapat menghasilkan media promosi dan pemasaran pariwisata secara efektif [13]. Dengan demikian, maka penelitian ini bertujuan "merancang sistem informasi promosi dan pemasaran objek wisata Guraici"

\section{METODE PENELITIAN}

\section{Analisis Sistem}

Analisis sistem menggunakan model driven secara terstruktur dengan pendekatan bottom-up, yaitu membuat konsep rancnagan system secara umum dengan menggunakan alat bantu flowchart. Sistem dibuat mulai dari admin yang berfungsi mengelola sistem, kemudian media penyimpanan, sampai pada luaran sistem. Selanjutnya sistem dirancang menggunakan alat bantu Diagram DFD, ERD dan Rancangan Tabel untuk rancangan databasenya serta Rancangan Layout untuk tampilan user interface system.

\section{Metode Pengembangan Sistem}

Metode pengembangan sistem yang digunakan adalah Waterfall Modelling dimana proses dilakukan secara berurutan [14], yaitu Perencanaan dan Analisis, Perancangan Sistem, kodingan, Implementasi, Operasi dan Pemeliharaan.



Gambar 1. Model Waterfall

\section{Road Map Penelitian}

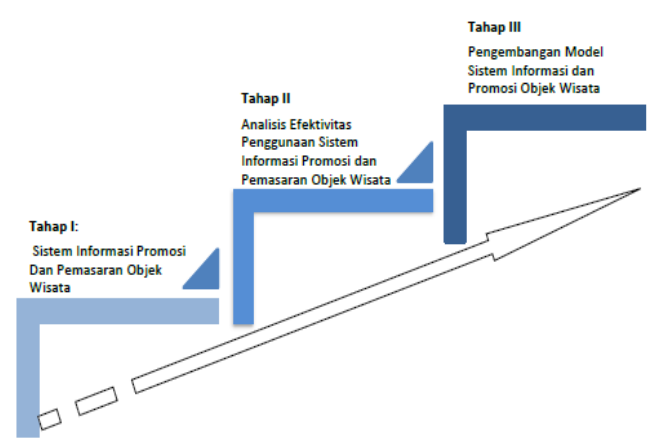

Gambar 2. Road Map Penilitian

\section{Kerangka Usulan Sistem}

Dari permasalahan sebelumnya maka pada penelitian ini maka 
peneliti akan merancang kerangka usulan sistem informasi yang baru untuk menunjang system yang lama sebagai berikut:

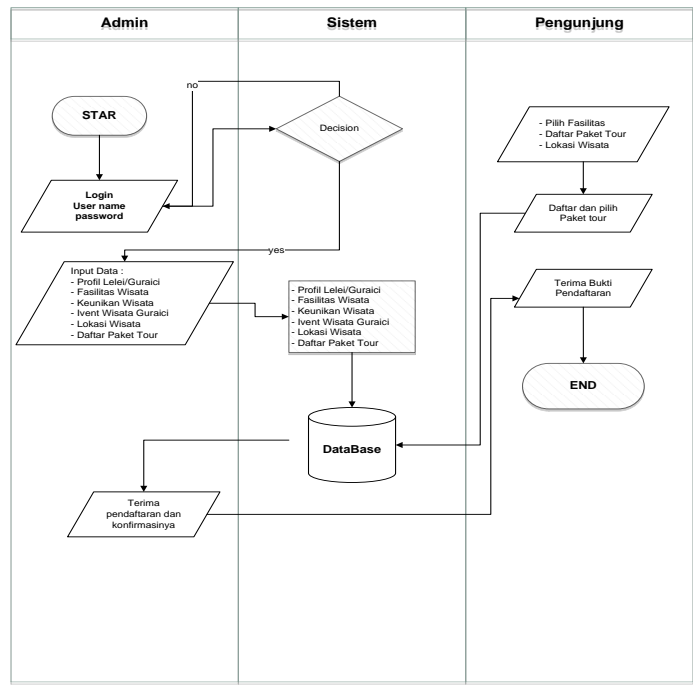

Gambar 3. Kerangka Usulan Sistem

Dari hasil rancangan umum

Kerangka konsep sistem informasi terdapat beberapa kelebihan yaitu:

1) Pengunjung yang ingin mecari informasi tenteng objek wisata Guraici dapat melihat pada sistem tanpa harus datang ke lokasi tersebut.

2) Pengunjung dapat melihat daftar paket tour pada sistem informasi yang terdapat pada objek wisata Guraici.

3) Objek wisata dapat dipromosikan melalui sistem secara terkomputerisasi;

4) Admin dapat memperbaharui informasi objek wisata dimana saja dan kapan saja pada sistem

RANCANGAN SISTEM

Diagram Konteks
Diagram Konteks merupakan rancangan alur sistem secara umum pada Sistem Informasi Pariwisata Guraici, berikut merupakan tampilan rancangan sistem diagram konteks alur proses di sajikan sebagai berikut:

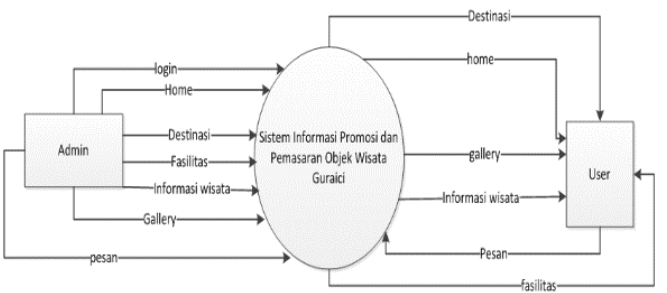

Gambar 4. Diagram Konteks

\section{Diagram Level Admin}

Data Flow Diagram Level admin merupakan proses pendetailan sistem untuk admin pengelolah data pada system Pada diagram level ini, proses sistem dipecah menjadi enam bagian proses utama, berikut merupakan Diagram Level:

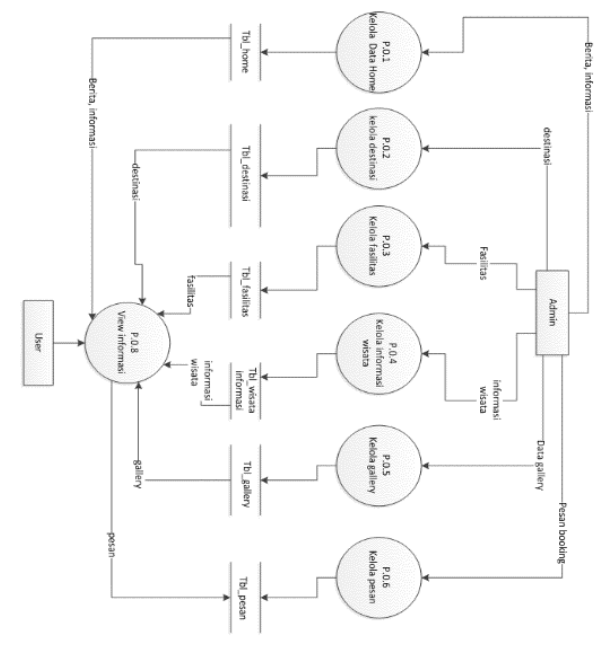

Gambar 5. Diagram Level Admin 


\section{Diagram Level User}

Diagram Level user merupakan rancangan proses pendetailan sistem, dimana user dapat melihat informasi yang ada pada menu, berikut merupakan gambar diagram level user:

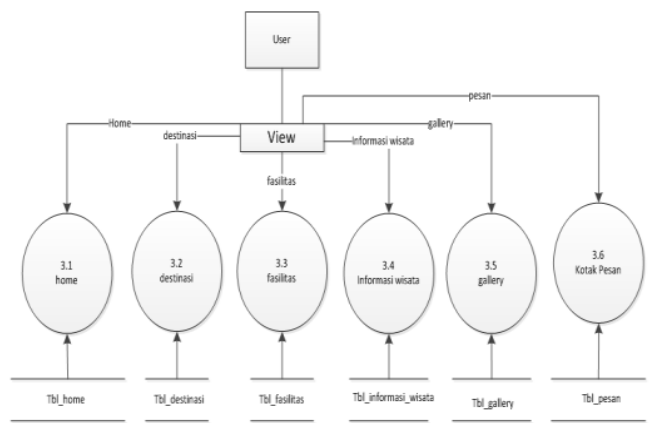

Gambar 6. Diagram Level User

\section{Rancangan ERD Relasi Table}

Rancangan ERD Relasi Tabel merupakan rancangan database system sebagai hubungan antar komponen Tabel system, berikut merupakan tampilan diagram yang di sajikan sebagai berikut

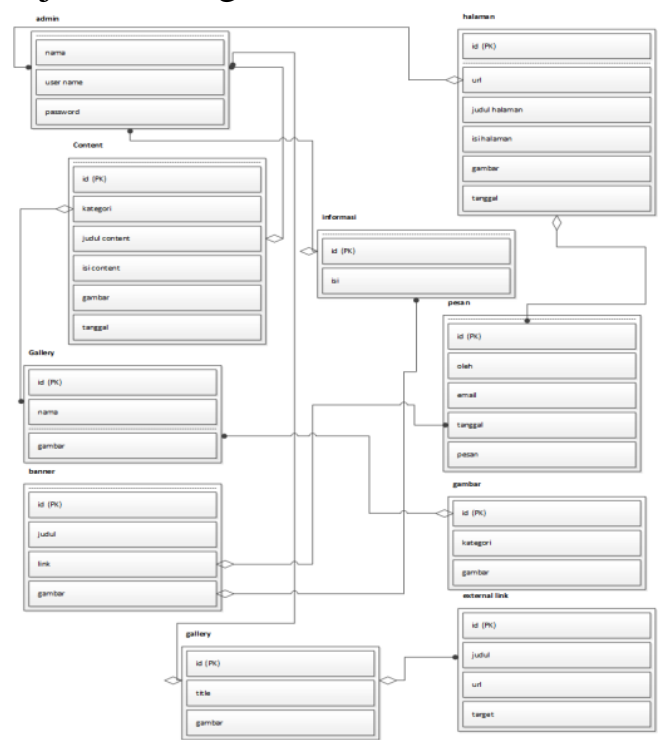

Gambar 7. ERD Relasi Tabel

\section{ERD Notasi}

Rancangan diagram Notasi merupakan rancangan database system sebagai hubungan antar komponen Entity system, berikut merupakan tampilan diagram yang di sajikan sebagai berikut

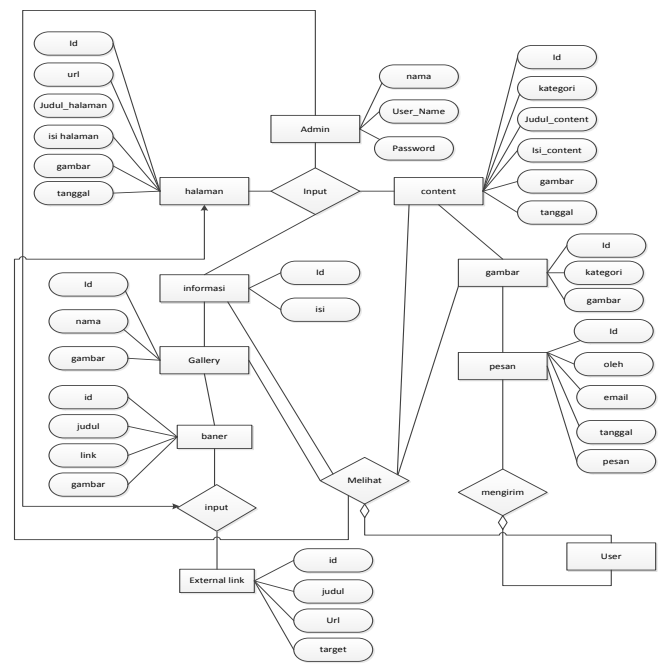

Gambar 8. ERD Notasi

\section{Rancangan Tabel}

Rancangan Tabel merupakan rancangan komponen-komponen database yang digunakan sebagai media penyimpanan data yang diinput dan di proses pada system nantinya, berikut merupakan beberapa tampilan rancangan table pada system:

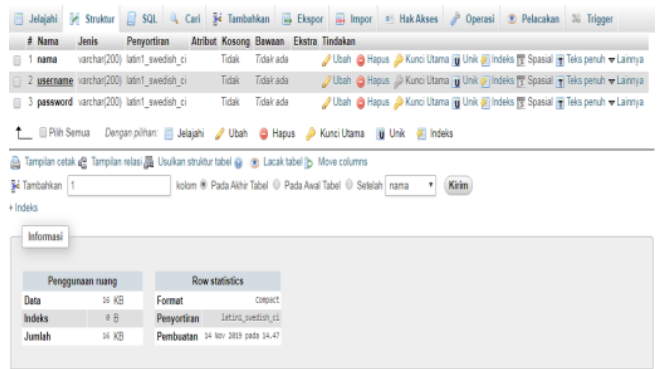

Gambar 9. Rancangan Tabel Admin 


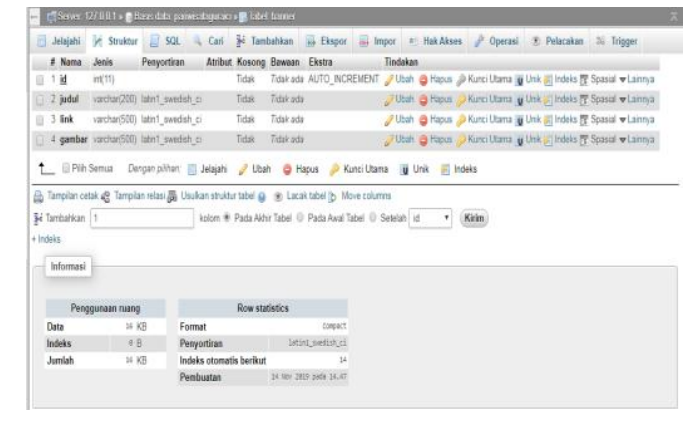

Gambar 10. Rancangan Tabel banner

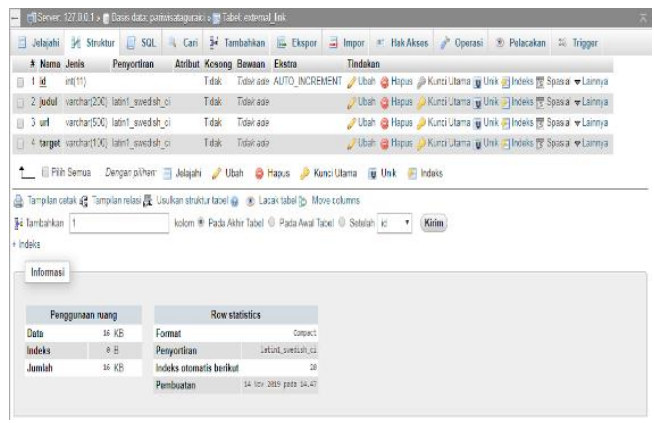

Gambar 11. Rancangan Tabel external_link

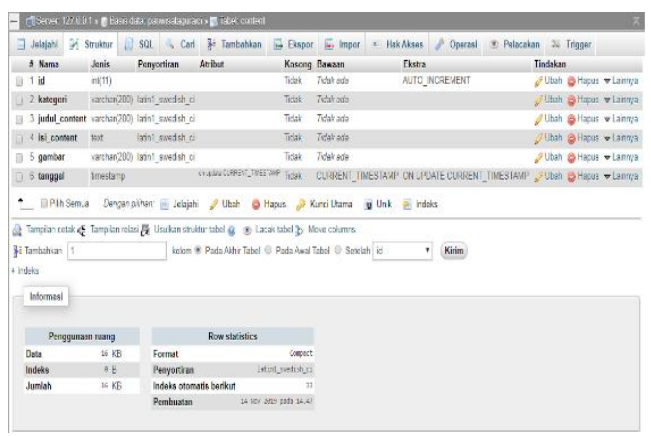

Gambar 12. Rancangan Tabel content

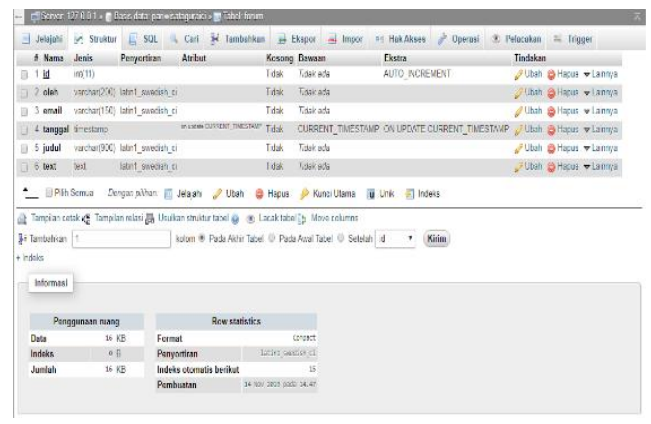

Gambar 13. Rancangan Tabel forum

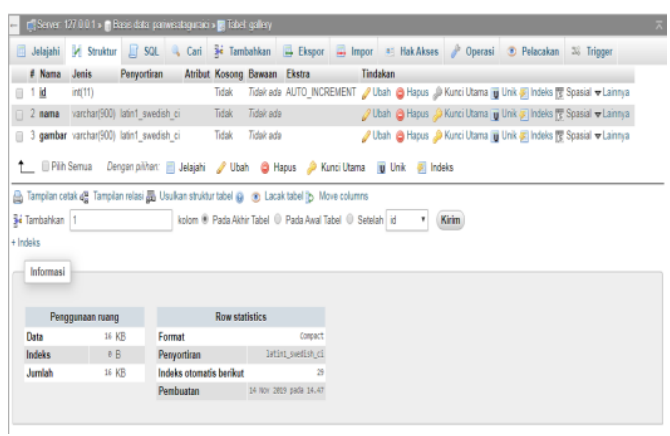

Gambar 14. Rancangan Tabel Gallery

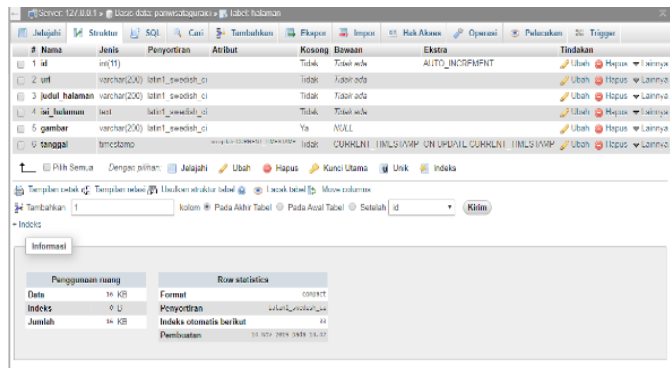

Gambar 15. Rancangan Tabel Halaman

\section{Rancangan Layout}

Rancangan Layout Sistem merupakan tampak awal rancangan dari setiap menu pada sistem yang akan digunakan sebagai acuan menu sistem yang akan diimplementasikan, berikut merupakan tampilan gambar rancangan layout menu system, berikut beberapa rancangan menu layoutnya:

\section{Layout Menu Utama}




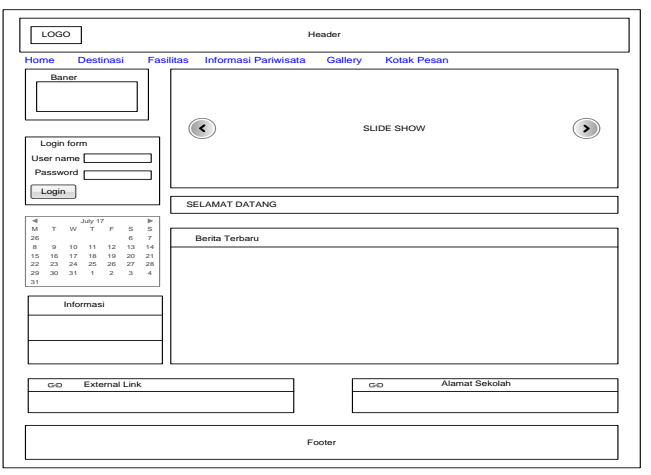

Gambar 16. Layout Menu Utama

Layout Menu Admin Kelola Data kontent

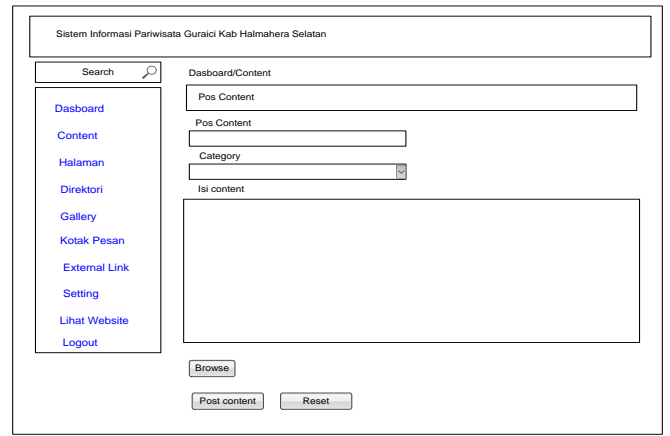

Gambar 17. Layout menu admin kelola konten

Layout Menu Admin Kelola Data halaman

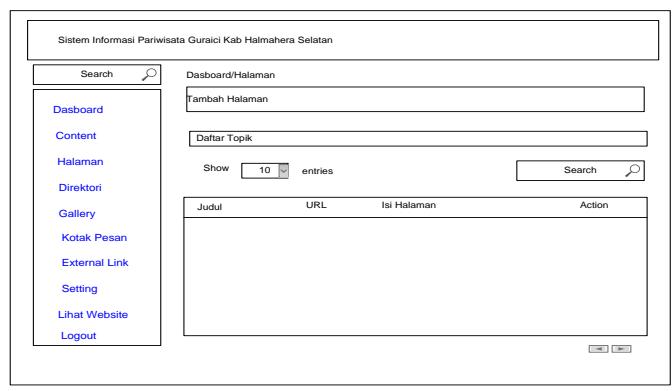

Gambar 18. Layout menu admin data halaman

Tampilan Layout Admin Kelola Data Gallery

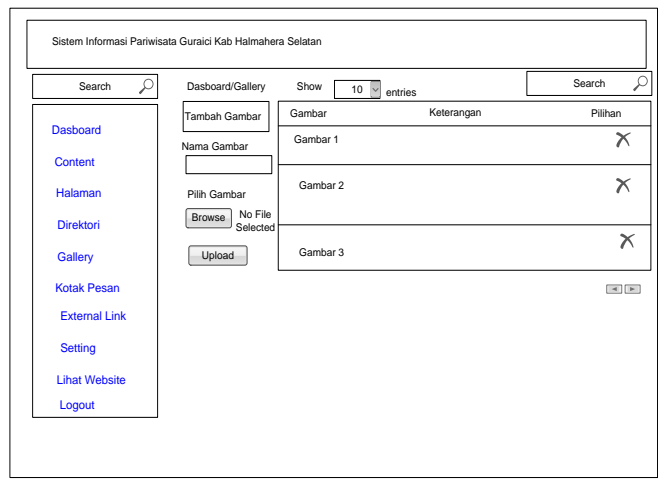

Gambar 19. Layout menu admin data gallery

Tampilan Layout Admin Kelola External Link

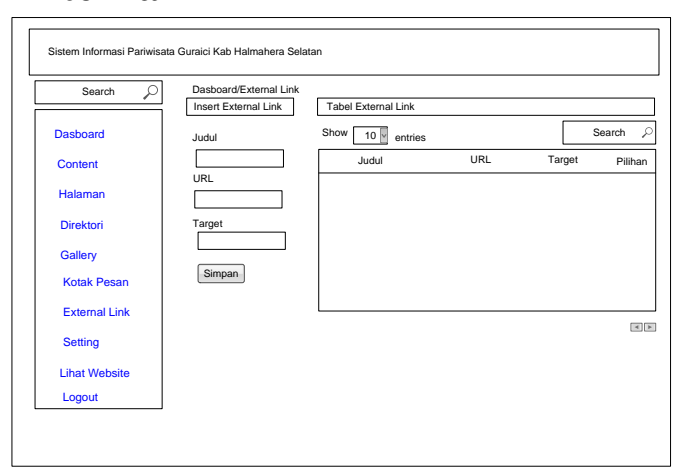

Gambar 20. Layout menu admin data pesan

\section{IMPLEMENTASI \\ PENGUJIAN SISTEM}

DAN

Implementasi

Sistem merupakan tahapan penerapan system yang sudah dibuat akan dipasangkan dan dijalankan pada PC yang seduah ditentukan, Berikut urutan dokumentasi penerapan system:

\section{Menu Home}


Menu home merupakan awal tampilan ketika user berkunjung di http://pariwisataguraici.com/

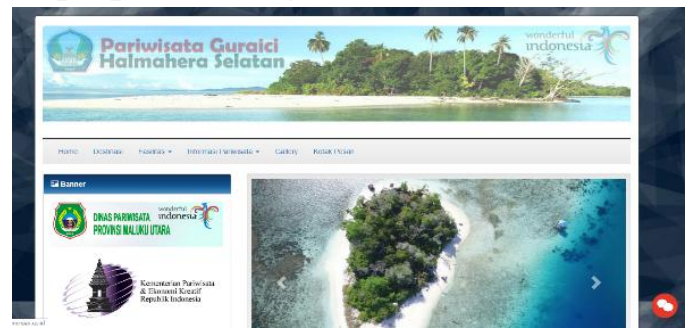

Gambar 21. Menu Home

\section{Tampilan Menu Destinasi}

Tampilan menu destinasi merupakan tampilan pengunjung unutk mengenal profil dari objek wisata pulau guraici, berikut merupakan gambar tampilan menunya:

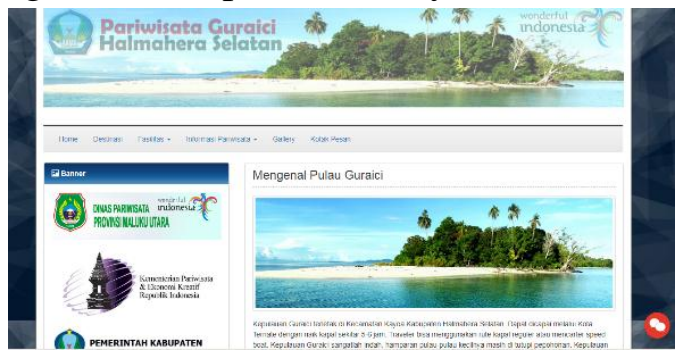

Gambar 22. Menu Destinasi

\section{Tampilan Menu Fasilitas}

Tampilan menu fasilitas merupakan tampilan informasi untuk mengenalkan fasilitas tempat tinggal yang ada di sekitar guraici, berikut gambar tampilan menu tersebut:

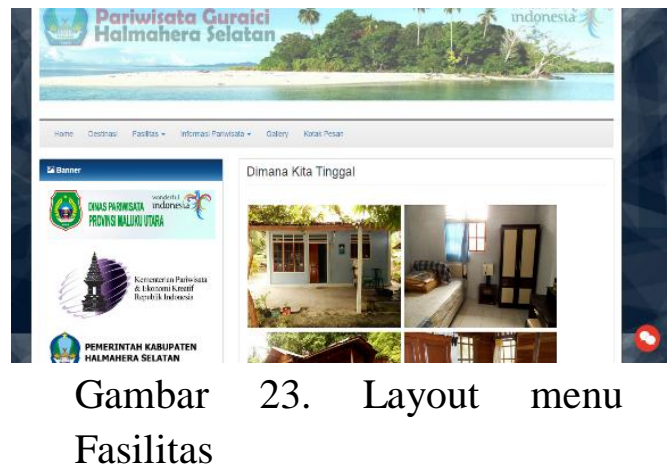

\section{Tampilan Menu Diving}

Tampilan menu diving merupakan informasi menu spot diving yang berada di sekitar pulau guraici, berikut merupakan gambar tampilan tersebut:

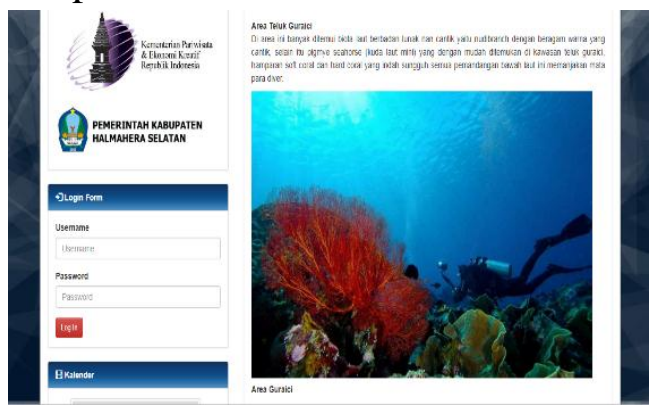

Gambar 24. Menu Diving

\section{Tampilan Menu Event}

Tampilan menu event merupakan menu informasi tentang acara wisata yang pernah dilakukan di kabupaten tersebut, berikut merupakan gambar tampilan menunya: 


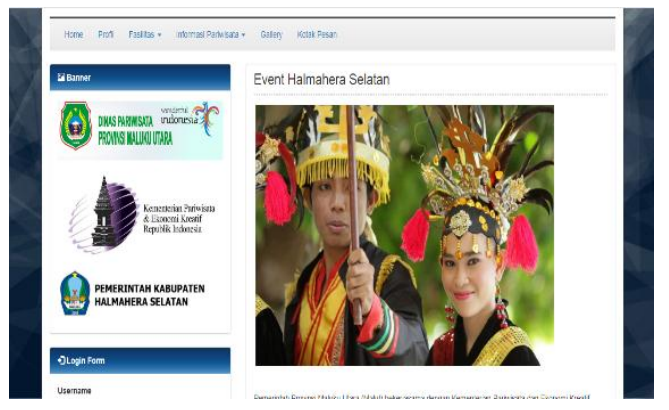

Gambar 25. Menu Event

\section{Tampilan Menu Gallery}

Menu gallery merupakan tampilan foto-foto spot yang ada di sekitar Guraici, berikut merupakan gambar tampilan menunya:

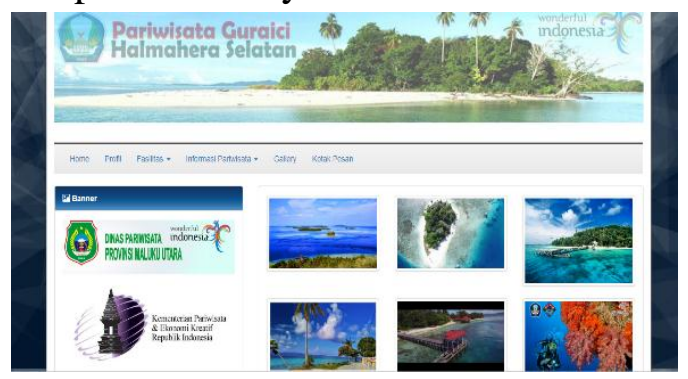

Gambar 26. Menu Gallery

\section{Tampilan Menu Kotak Pesan}

Tampilan kotak pesan merupakan menu tentang forum dan kotak pesan yang disediakan untuk user yang saling bertanya, pesan tempat dan melihat lokasi peta, bias juga menggunakan live chat pada icon chat di kanan bawah, berikut merupakan gambar tampilan menunya:

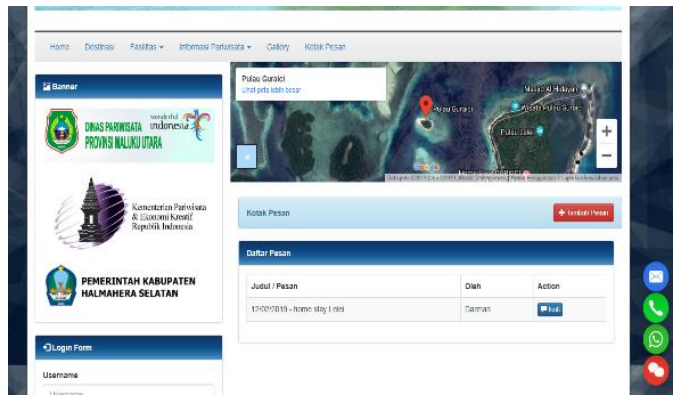

Gambar 27. Menu Kotak Pesan

\section{Pengujian Sistem}

Model Pengujian Sistem yang digunakan adalah model Blackbox yaitu menguji fungsi dari setiap menu-menu yang ada pada system agar dapat mengetahui kegagalan system yang akan dijalankan, berikut table uji system blackbox.

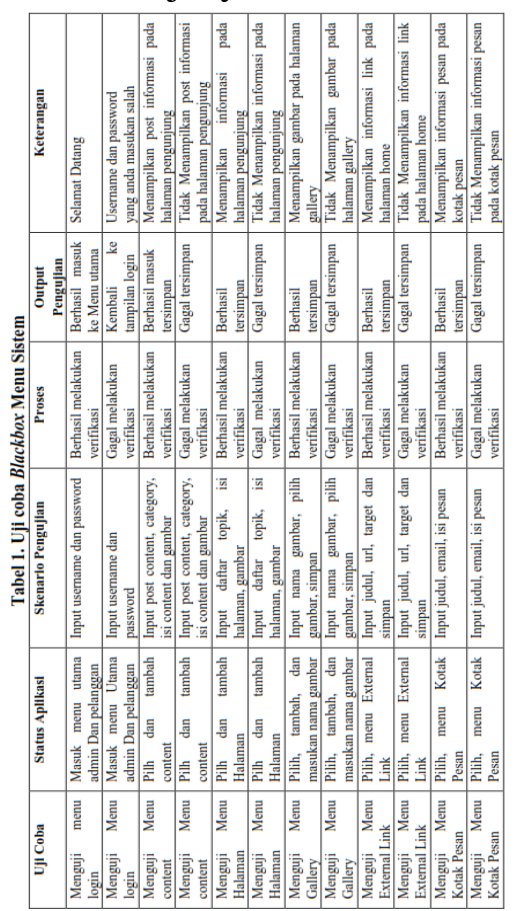

\section{Kesimpulan}

Penelitian menghasilkan sistem informasi berbasis website 
yang berfungsi sebagai media promosi dan pemasaran objek wisata desa Guraici. Sistem informasi ini dapat menjangkau masayarakat di seluruh dunia, serta memudahkan masyarakat mengakses objek dan produk wisata yang ada di Desa Guraici secara online.

Hasil pengujian sistem menunjukan fungsi akses pada setiap menu-menu berjalan baik dan tidak error. Data informasi yang diinput dapat diproses oleh sistem dan menunjukan hasil luaran pada database dan direspon oleh masing-masing komponen sistem. Dengan demikian, disarankan kepada pemerintah desa Guraici untuk memanfaatkan sistem informasi berbasis website.

Sistem informasi ini masih terbatas sebagai media komunikasi dalam hal promosi dan pemasaran, dan belum menyedikan proses transaksi pembelian produk secara online. Oleh karena itu, masih diperlukan pengembangan sistem mengenai lokasi pemetaan objek wisata, jarak tempuh, dan pada model menu kotak pesan perlu ada penyajian menu interaktif agar pengunjung dapat melakukan pemesanan dan booking paket produk wisata.

\section{Ucapan Terima Kasih}

Peneliti mengucapkan terima kasih kepada kemenristekdikti yang telah memberikan dukungan dalam pendanaan Penelitian Dosen Pemula Tahun 2018-2019.

\section{DAFTAR PUSTAKA}

[1] BPS Indonesia, 2017. Statistik Indonesia. Katalog:1101001. BPS Indonesia.

[2] Çoban, Ayse., Duygu B.Kurt and Orhan Ç, An Analysis Of Tourism Sector With The Grubel-Lloyd Index: The Case Of Turkey And Selected Countries.

International

Journal of Arts \& Sciences, 08 (07):223-231, 2015.

[3] Buckley, Ralf (2012). Sustainable Tourism: Research and Reality. Annals of Tourism Research, Vol. 39, No. 3, pp. 528-546, available at www.elsevier.com/locate/atour es.

[4] Swarbrooke, John (1999). Sustainable Tourism Management. New York: Cabi Publishing.

[5] Muljadi Dan Warman, 2009. Kepariwisataan dan Perjalanan (Edisi revision 2016), Rajagrafindo Persada, Jakarta..

[6] Ramdas, M, and Mohamed, B, 2014. Impacts of tourism on environmental attributes, environmental literacy, and willingness to pay: A conceptual and theoretical review. Procedia-Social and Behavioral Sciences 144 pp 378-391, available www.sciencedirect.com. 
[7] Othman, Pazim, and Rosli, M. Mohd. 2011. The Impact of Tourism on Small Business Performance: Empirical Evidence from Malaysian Islands. International Journal of Business and Social Science Vol. 2 No. 1; January 2011. pp.11-21, available at www.ijbssnet.com.

[8] Kemenpar

(Kementerian

Pariwisata Republik Indonesia). 2014. Laporan Kinerja Kementrian Pariwisata. Jakarta, Tahun 2014.

[9] BPS Halmahera Selatan, 2017. Maluku Utara Dalam Angka. SUSENAS: Katalog: 1102001.82. Provinsi Maluku Utara: Kantor BPS Halsel.

[10] Muharto., B. Tewal., S. L Mandey, and A. Tumbel. 2017. Competitiveness And The Increasing Strategy Of Competitiveness In Tourism Sector Of Ternate City, North Maluku Province. International Journal of Life Economics 4 (14): 11-32.

[11] Muharto. 2018. The Sustainability Of Tourism Competitiveness In Ternate. Journal of Life Economics, Vol.5, No.4, Pp.7596.

[12] Bethapudi, Anand. 2013. The Role Of ICT In Tourism Industry. Journal Of Applied Economics And Business 1 (4): 67-79.
[13]Prasetya, D. Dwi. 2011. Aplikasi Virtual Tour Berbasis Web Sebagai Media Promosi Pariwisata. Seminar On Electrical, Informatics, and Its Education (2011): 58-63

[14] Muharto \& Ambarita, A. 2016. Metode Penelitian Sistem Informasi: Mengatasi Kesulitan Mahasiswa Dalam Menyusun Proposal Penelitian. Yogyakarta: Deepublish. 